\title{
BMJ Open Climate change, climate-related disasters and mental disorder in low- and middle-income countries: a scoping review
}

Isobel Sharpe, Colleen M Davison

To cite: Sharpe I, Davison CM. Climate change, climaterelated disasters and mental disorder in low- and middle-income countries: a scoping review. BMJ Open 2021;11:e051908. doi:10.1136/ bmjopen-2021-051908

- Prepublication history and additional supplemental material for this paper are available online. To view these files, please visit the journal online (http://dx.doi.org/10.1136/ bmjopen-2021-051908).

This study was presented as a poster at the 2020 Canadian Conference for Global Health.

Received 31 March 2021 Accepted 01 October 2021

\section{Check for updates}

(c) Author(s) (or their employer(s)) 2021. Re-use permitted under CC BY-NC. No commercial re-use. See rights and permissions. Published by BMJ.

Department of Public Health Sciences, Queen's University, Kingston, Ontario, Canada

Correspondence to Dr Colleen M Davison; davisonc@queensu.ca

\section{ABSTRACT}

Introduction Climate change and climate-related disasters adversely affect mental health. Low- and middleincome countries (LMICS) are particularly vulnerable to the impacts of climate change and climate-related disasters and often lack adequate mental healthcare infrastructure. We used the scoping review methodology to determine how exposure to climate change and climate-related disasters influences the presence of mental disorders among those living in LMICs. We also aimed to recognise existing gaps in this area of literature.

Methods This review followed the Preferred Reporting Items for Systematic reviews and Meta-Analyses extension for Scoping Reviews checklist. To identify relevant studies, we searched five electronic databases (MEDLINE, EMBASE, Global Health, APA Psyclnfo and Sociological Abstracts) from 1 January 2007 to 31 December 2019. We also searched the grey literature. Included studies had an adultfocused LMIC population, a climate change or climaterelated disaster exposure and a mental disorder outcome. Relevant study information was extracted and synthesised. Results Fifty-eight studies were identified, most of which $(n=48)$ employed a cross-sectional design. The most commonly studied exposure-outcome combinations were flood-related post-traumatic stress disorder (PTSD) $(n=28)$, flood-related depression $(n=15)$ and storm-related PTSD $(n=13)$. The majority of studies identified a positive exposure-outcome association. However, few studies included a baseline or comparator (ie, unexposed) group, thereby limiting our understanding of the magnitude or nature of this association. There was also great heterogeneity in this literature, making studies difficult to pool or compare. Several research gaps were identified including the lack of longitudinal studies and nonuniformity of geographic coverage.

Conclusion To our knowledge, this was the first scoping review to investigate the relationship between climate change and climate-related disaster exposures and mental disorder outcomes in LMICs. Our findings support the need for further research, but also highlight that mental health should be a priority within LMIC climate change policy considerations.

\section{INTRODUCTION}

It is undeniable that human activities are warming the climate at an unprecedented rate. The average global surface temperature

\section{Strengths and limitations of this study}

To our knowledge, this was the first scoping or systematic review to assess how exposure to climate change and climate-related disasters influences the presence of mental disorders among those living in low- and middle-income countries.

- The review was conducted using rigorous methods, upholding the Preferred Reporting Items for Systematic reviews and Meta-Analyses standards for scoping reviews. This included a thorough search of both the academic and grey literature, as well as the use of two independent reviewers for study screening.

- Owing to project feasibility, our review was limited to English-language studies only. This is a common limitation of scoping reviews.

- We identified a lack of studies with baseline/comparator groups, which made it challenging to determine the full extent of the association between climate change and climate-related disaster exposures and mental disorder outcomes in this population.

rose by $0.85^{\circ} \mathrm{C}$ between 1880 and 2012 and this increase will likely exceed $2^{\circ} \mathrm{C}$ by the end of the century if inadequate action is taken. ${ }^{1}$ These environmental changes severely impact both our natural and human systems. Climate change reduces crop yields and biodiversity and increases sea levels and extreme weather events. This contributes to catastrophic social and economic disruptions such as poverty and displacement, as well as an increased burden on our health and healthcare systems. Indeed, the 2009 Lancet Commission on Managing the Health Effects of Climate Change recognised this issue as 'the biggest global health threat of the 21st century'.

When exploring the health impacts of climate change, it is important to consider both our physical and mental health. Mounting evidence supports a link between climate change and poor mental health, 
largely through two main pathways: direct and indirect. ${ }^{3}$ Direct impacts involve psychological trauma due to climate-related disasters such as floods, ${ }^{45}$ storms, ${ }^{67}$ wildfires ${ }^{89}$ and heatwaves. ${ }^{1011}$ Indirect impacts involve mental health problems associated with broader climate changerelated events such as gradual temperature increase and displacement. For example, rising sea levels may contribute to population displacement, resulting in mental health problems associated with overcrowding and poverty. ${ }^{12} 13$

The Intergovernmental Panel on Climate Change (IPCC) has recognised that the mental health consequences of climate change and climate-related disasters often burden already vulnerable populations. ${ }^{14}$ Indeed, those living in low- and middle-income countries (LMICs) disproportionately suffer from the negative effects of climate-related disasters and from broader environmental changes such as reduced crop yields. ${ }^{15} 16$ LMICs also commonly lack adequate infrastructure for mental health services. ${ }^{1718}$ These factors emphasise the reality of climate change as a health equity issue. ${ }^{2}$

As of present, few studies have attempted to synthesise existing research on climate change, climate-related disasters and mental health in LMICs. Rataj et $a l^{19}$ and Crabtree ${ }^{20}$ conducted systematic searches on the direct negative mental health impacts of climate-related weather events in developing countries; however, they did not explore the indirect impacts of climate change on mental health. Additionally, although this field of research is rapidly growing, there has been no review of recent literature published within the past 5 years. In comparison to other aspects of mental health, mental disorders are highly burdensome. In 2010, mental, neurological and substance abuse disorders accounted for $10.4 \%$ of all disability-adjusted life-years globally. ${ }^{21}$ Therefore, assessing the presence of mental disorders is particularly relevant within the context of climate change and climate-related disasters. This study used the scoping review methodology to determine how exposure to climate change and climate-related disasters influences the presence of mental disorders among those living in LMICs. Our secondary objective was to recognise existing gaps in this area of literature, allowing for future research and/or policy efforts targeted towards these areas.

\section{METHODS}

Scoping reviews systematically identify and map the evidence base of a particular topic as well as identify existing gaps in the literature..$^{22}$ They are often used when a body of literature is heterogeneous in nature. In this case, the settings and methodologies of studies investigating climate change and mental health vary widely. The review took place between May 2020 and March 2021 and followed the Preferred Reporting Items for Systematic reviews and Meta-Analyses extension for Scoping Reviews (PRISMA-ScR) checklist ${ }^{23}$ as well as recommendations from the Arksey and O'Malley ${ }^{24}$ framework and the Joanna Briggs Institute (JBI) Reviewer's Manual. ${ }^{25}$

\section{Eligibility criteria}

This review included primary studies that took place in LMICs and assessed either the relationship between climate change and mental disorders or the relationship between climate-related disasters and mental disorders (table 1, online supplemental file 1). Populations located entirely in LMICs, as defined by the World Bank, ${ }^{26}$ were included. Our review focused on adults, defined as studies where the mean age of the sample was $>18$ years. We chose this definition because we felt it was important to capture studies that primarily included adults but also may have included a small proportion of children (given that this situation was common within our area of literature).

Climate change is a complex and multifaceted concept and therefore no single variable can represent it as a whole. To capture both the direct and indirect effects of climate change, we used two main criteria for the study exposures. Studies were included if their exposure was either a climate-related natural disaster (direct effects) or explicitly mentioned by the study author as 'climate change' (indirect effects). The mental disorder outcomes of interest were anxiety, depression, post-traumatic stress, acute stress, substance use and addiction, bipolar, schizophrenia, suicidal behaviour and non-suicidal self-injury. Studies were included if they were published in 2007 or later, given that the majority of relevant research has occurred since this time. ${ }^{27}$ Additionally, for feasibility reasons only English-language studies were included.

\section{Information sources and search strategy}

To capture all relevant records, both electronic databases and the grey literature were searched. Detailed search strategies are presented in online supplemental file 2. The searches were conducted between August and September 2020 to identify records published online between 1 January 2007 and 31 December 2019. The following five electronic databases were searched: MEDLINE via Ovid (biomedicine, 1946-present), Embase via Ovid (biomedicine and pharmacology, 1947-present), APA PsycInfo via Ovid (psychological, social, behavioural and health sciences, 1806-present), Global Health via Ovid (global health, 1910-present) and Sociological Abstracts via ProQuest (sociology, 1952-present). The database search strategy was designed in consultation with a health sciences librarian, first developed in MEDLINE and subsequently translated to the other databases.

To capture relevant studies that may not have yet been indexed in the electronic databases, we also performed a manual search of the 2019 volumes of the following journals: International Journal of Environmental Research and Public Health, Global Environmental Change, Climatic Change, Disaster Medicine and Public Health Preparedness, and Environmental Health. Additionally, the reference lists of all studies included at the full-text stage were searched (ie, backward snowballing). Included studies were also 
Table 1 Scoping review inclusion and exclusion criteria

\begin{tabular}{|c|c|c|}
\hline & Inclusion criteria & Exclusion criteria \\
\hline Population & $\begin{array}{l}\text { Adult-focused (study population with mean age }>18 \\
\text { years) } \\
\text { Study population located entirely in low- and middle- } \\
\text { income countries at time of exposure (may be located } \\
\text { in more than one) }\end{array}$ & $\begin{array}{l}\text { Child-focused (study population with mean } \\
\text { age } \leq 18 \text { years) } \\
\text { Any part of the study population located in } \\
\text { high-income countries }\end{array}$ \\
\hline $\begin{array}{l}\text { Intervention } \\
\text { (Exposure) }\end{array}$ & $\begin{array}{l}\text { Climate-related disaster exposure (see online } \\
\text { supplemental file } 1 \text { for list of climate-related } \\
\text { disasters) OR climate change-related exposure (as } \\
\text { identified by the study author) } \dagger\end{array}$ & \\
\hline Comparison & Any & \\
\hline Outcome & $\begin{array}{l}\text { Mental disorders (anxiety, depression, post-traumatic } \\
\text { stress, acute stress, substance use and addiction, } \\
\text { bipolar, schizophrenia, suicidal behaviour, non- } \\
\text { suicidal self-injury) evaluated based on DSM or ICD } \\
\text { symptoms }\end{array}$ & $\begin{array}{l}\text { Mental disorders not evaluated based on } \\
\text { DSM or ICD symptoms } \\
\text { - Study only measures positive mental health }\end{array}$ \\
\hline
\end{tabular}

*Based on the World Bank's designation of a low- and middle-income country (includes low, lower-middle and upper-middle income economies). ${ }^{26}$

†Climate change is a challenging concept to define and measure. We chose to include studies where the study author explicitly mentioned that they were investigating the effects of climate change (eg, used the words 'climate change' when describing the study exposure). $\ddagger$ The IPCC's fourth assessment report (AR4) was published in 2007, in which the authors began to acknowledge the impacts of climate change on human health and well-being. This approach was taken in a similar scoping review by Middleton and colleagues. ${ }^{27}$

.DSM, Diagnostic and Statistical Manual of Mental Disorders; ICD, International Classification of Diseases ; IPCC, Intergovernmental Panel on Climate Change.

searched in Google Scholar to identify any relevant studies that had cited them (ie, forward snowballing).

The grey literature search strategy was adapted from Godin $e t a l^{28}$ and consisted of three main approaches. First, targeted website browsing/searching was performed. A list of relevant organisations was generated through the authors' personal knowledge and Google searches of relevant keywords. If the organisation's website did not contain a search feature, we browsed for relevant records. If the website contained a search feature, a search was also performed and the first 100 results were scanned for relevance. Second, grey literature databases were searched, including Google Scholar, BIOSIS Previews and ProQuest Dissertations \& Theses Global. The first 100 results of each search were scanned. Third, the popular search engines Google and DuckDuckGo were searched and the first 100 results were assessed.

\section{Screening}

The Covidence systematic review software was used to organise studies throughout the screening process (https://www.covidence.org/, Veritas Health Innovation, Melbourne, Australia). All search results were uploaded into Covidence and duplicate records were removed. For feasibility reasons, one reviewer performed a relevancy screen of all unique records. This was done by scanning the title and abstract of each record and excluding those studies clearly irrelevant to the research question (those that did not have an exposure related to climate change or the environment, did not have an outcome related to mental health, did not take place in a LMIC, or were not primary research). Next, the titles/abstracts of each remaining record were screened by two independent reviewers and those deemed irrelevant were excluded. The reviewers discussed any conflicts and came to mutual agreement. The remaining studies were screened for eligibility at the full-text level by two reviewers. At this stage, specific reasons for exclusion were chosen based on the following hierarchy: (1) duplicate, (2) non-English language, (3) wrong study design, (4) wrong population, (5) wrong exposure and (6) wrong outcome. Again, conflicts were resolved through discussion and mutual agreement.

\section{Data collection and analysis}

On finalising the list of included studies, data extraction was completed using a Microsoft Excel form (online supplemental file 3). Information was collected on study design (setting, population, sample size, exposures, outcomes and length of follow-up), baseline 


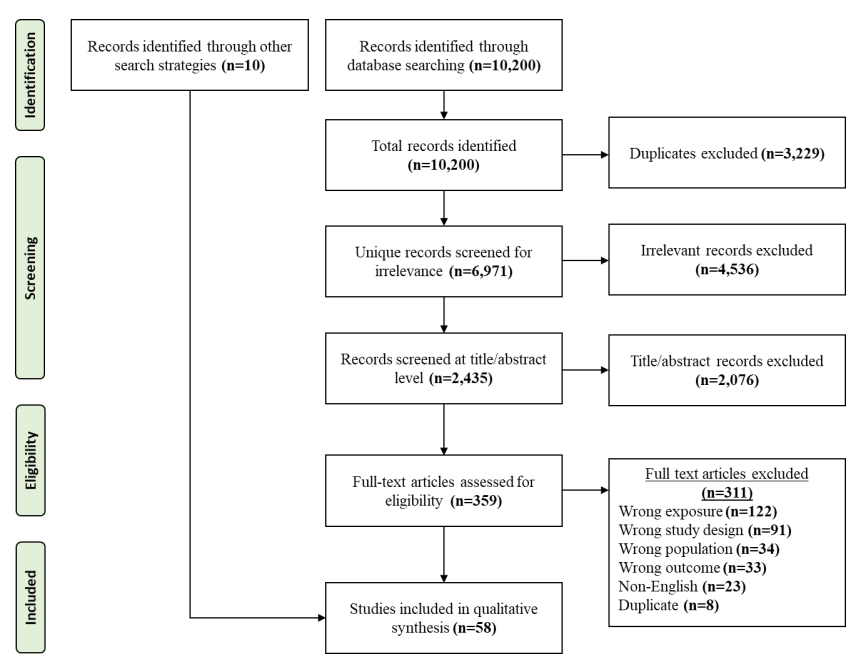

Figure 1 Preferred Reporting Items for Systematic reviews and Meta-Analyses flow diagram. A total of 58 studies were included in this review.

characteristics, qualitative findings and quantitative findings (including measures of effect). Prior to beginning the extraction process, the form was piloted on a random sample of five studies and adjusted accordingly. The final results were synthesised in the form of qualitative descriptions, tables, frequency counts and conceptually relevant diagrams.

\section{Patient and public involvement}

This review was an analysis of previously published literature. Thus, patients and the public were not directly involved in its design, conduct, reporting or dissemination.

\section{RESULTS}

\section{Overview}

A total of 10200 records were identified through the electronic database searches. No studies were identified through the grey literature search. Of the identified records, 3229 were excluded as duplicates and a further 4536 were excluded through the single-author relevancy screen. Two independent reviewers screened the remaining 2435 records at the title/abstract level and 2076 were excluded. The resulting 359 records were assessed for eligibility at the full-text level and 311 were excluded. Ten eligible records were identified through the manual searches (ie, backward and forward snowballing), contributing to a total of 58 included studies. Figure 1 displays the PRISMA flow diagram and online supplemental file 4 contains the details of all included studies.

As shown in figure 2, the included studies took place in 11 countries. China and India were the countries of study location most frequently $(\mathrm{n}=14 \mathrm{each})$, followed by Pakistan $(n=7)$ and Vietnam $(n=6)$. The included countries spanned 4 of the 19 United Nations (UN) subregions. Most studies employed a cross-sectional design ( $\mathrm{n}=45$ cross-sectional; $\mathrm{n}=3$ repeated cross-sectional).

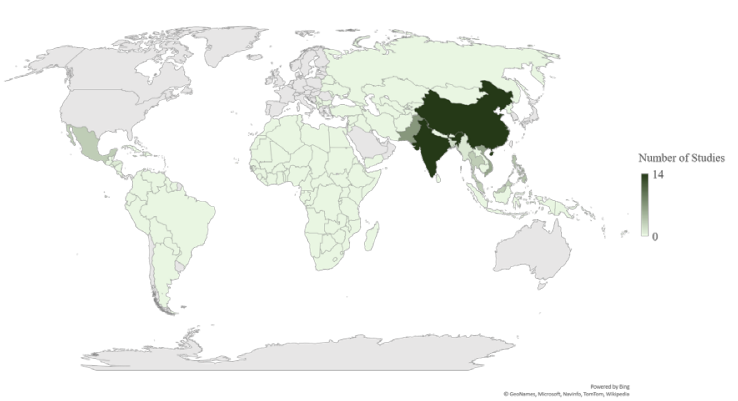

Figure 2 World map showing the number of included studies conducted in each country. $n=14$ studies took place in China, $n=14$ in India, $n=7$ in Pakistan, $n=6$ in Vietnam, $\mathrm{n}=4$ in the Philippines, $\mathrm{n}=3$ in Thailand, $\mathrm{n}=3$ in Malaysia, $\mathrm{n}=3$ in Mexico, $n=2$ in Bangladesh, $n=1$ in Myanmar and $n=1$ in Honduras. The high-income countries are coloured in grey.

Other studies used prospective cohort $(n=5)$, ecological $(\mathrm{n}=4)$ and case-crossover $(\mathrm{n}=1)$ designs. Sample sizes of the included studies ranged substantially, with $36 \%$ of studies under $250,40 \%$ between 250 and 1000, and $22 \%>1000$ (note: one qualitative study did not report a sample size). Eleven studies were published between 2007 and 2012, compared with 47 published between 2013 and 2019. Although this review focused on LMICs, a total of 11 studies were published with high-income country-only authorship.

Most (91\%) studies investigated the effects of climaterelated disasters on mental disorder (direct effects), while fewer $(9 \%)$ investigated the broader effects of climate change on mental disorder (indirect effects). Table 2 shows the total number of studies assessing any given combination of climate change or climate-related disaster exposure and mental disorder outcome. The five most popular combinations were post-traumatic stress disorder (PTSD) in a flood setting ( $\mathrm{n}=28)$, depression in a flood setting $(n=15)$, PTSD in a storm setting $(n=13)$, anxiety in a flood setting $(n=11)$ and anxiety in a storm setting $(n=10)$. Flood exposures were by far the most studied. The next most popular exposure was storms (including typhoons, hurricanes and snowstorms), followed by extreme temperatures. PTSD outcomes were reported the most often, followed by depression and anxiety. Comparatively few studies explored acute stress disorder (ASD), substance use and suicide outcomes. Of those studies reporting, length of follow-up ranged from 3 weeks to 17 years. Most $(n=30)$ studies followed up within a year.

The included studies used a variety of tools to measure mental disorder outcomes. A number of studies used formal diagnoses, obtained through clinician interviews based on the Diagnostic and Statistical Manual of Mental Disorders (DSM) or International Classification of Diseases (ICD) criteria. For example, Kim and colleagues $^{29}$ conducted a physician assessment of PTSD and ASD based on DSM-IV criteria. Alternatively, other studies used screening instruments with validated cut-off scores to establish an informal mental disorder diagnosis. Idris $e t a l^{30}$ measured PTSD using the Trauma Screening 
Table 2 A matrix of the included studies $(n=58)$, showing the number of studies investigating a given climate-related disaster or climate change exposure and mental disorder outcome

\begin{tabular}{lcccccccc}
\hline & PTSD & ASD & Anxiety & Depression & Substance use & Suicide & Other $^{*}$ & TOTAL† \\
\hline Drought & - & - & 1 & 2 & - & 1 & - & 4 \\
Extreme temperature & 2 & 2 & 2 & 2 & 2 & - & 4 & 14 \\
Flood & 28 & - & 11 & 15 & 2 & 1 & 3 & 60 \\
Landslide & - & - & - & - & - & - & - & 0 \\
Storm & 13 & 2 & 10 & 9 & 1 & 1 & - & 36 \\
Displacement & 2 & - & 1 & 2 & - & - & - & 5 \\
Temperature/ precipitation & - & - & - & - & - & 2 & 1 & 3 \\
Totalł & 45 & 4 & 25 & 30 & 5 & 5 & 8 &
\end{tabular}

The climate-related disaster exposures (direct effects) are highlighted in light green and the broader climate change exposures (indirect effects) are highlighted in dark green.

*Including: schizophrenia, bipolar affective disorder, any mental disorder.

†For those studies that identified multiple exposure categories for a single climate change or climate-related disaster event (ie, a natural disaster that resulted in both flooding and landslides), we chose the primary exposure category. Therefore, each study is associated with a single climate change exposure.

$\ddagger$ Many studies investigated more than one type of mental disorder outcome.

ASD, acute stress disorder; PTSD, post-traumatic stress disorder.

Questionnaire, a 10-item tool derived from DSM-IV criteria (where a score of $\geq 6$ is considered the optimal cut-off point for PTSD).$^{31}$ The subsequent sections discuss further details of the study findings within each UN subregion. Furthermore, table 3 outlines the available evidence for the association between climate change and climaterelated disaster exposures and mental disorder outcomes in each subregion.

\section{South Asia}

Twenty-three studies were conducted in South Asia, with 14 in India, ${ }^{32-45} 7$ in Pakistan ${ }^{46-52}$ and 2 in Bangladesh. ${ }^{5354}$ Many of these studies focused on specific populations, including women,${ }^{475}$ farmers, ${ }^{36}$ primary care attendees ${ }^{43}$ and postdisaster relief camp attendees. ${ }^{414} 46485051$ The majority $(74 \%)$ of studies assessed a flood-related exposure ( $\mathrm{n}=15$ direct effects of flooding, $\mathrm{n}=2$ broader floodrelated displacement), where mental disorder prevalence ranged from $0.2 \%$ to $100 \%$ for PTSD, $0.7 \%$ to $61.5 \%$ for depression and $0.1 \%$ to $44 \%$ for anxiety. The remaining studies assessed the following exposures: droughts $(n=2)$, cyclones $(n=3)$ and cumulative temperature and precipitation $(\mathrm{n}=1)$.

All but one of the 23 studies used a cross-sectional or repeated cross-sectional design. Furthermore, one study was qualitative, ${ }^{39}$ two were mixed methods ${ }^{42}{ }^{44}$ and the remainder were quantitative. Crabtree ${ }^{39}$ qualitatively explored disaster-related experiences and PTSD symptoms among community members after the 2008 Kosi River floods. Semistructured interviews and informal conversations revealed that many individuals were experiencing symptoms of PTSD and depression up to 18 months post flood. Speaking of their experiences in disaster relief camps, women commented that they were 'indecisive and helpless', and in a state of 'numbness', with their 'senses not working,. ${ }^{39}$
Three of the 23 studies included some type of baseline/comparator (ie, unexposed) group, all of which reported a positive exposure-outcome relationship. For example, Wind $e t a l^{34}$ found significantly higher scores for both depression and anxiety among flood-exposed individuals compared with unexposed individuals (both $\mathrm{p}<0.001)$. While the remainder of studies did not contain an unexposed group, nine assessed climate change or climate-related disaster exposure severity as a risk factor for mental disorder outcomes and most reported a positive association between the two. For instance, Viswanathan $e t a l^{36}$ found that presence of both depression and suicidal ideation was significantly higher among farmers whose yield was completely eliminated due to drought compared with those whose yield was not substantially reduced ( $\mathrm{p}=0.004$ depression, $\mathrm{p}=0.009$ suicidal ideation $)$. Suar and colleagues ${ }^{37}$ reported a significant association between cyclone proximity and both anxiety $(\mathrm{p}<0.01)$ and depression $(\mathrm{p}<0.05)$, but not PSTD $(\mathrm{p}>0.05)$. The remaining studies did not directly explore the association of interest, solely reporting mental disorder prevalence rates among those exposed to a climate change or climate disaster event. Rahman et $a \tilde{l}^{\tilde{1}}$ and Solangi et a $a \tilde{l}^{2}$ both studied flood-related displacement, a broader climate change-related exposure. The former study reported a 9\% prevalence of PTSD and $44 \%$ prevalence of depression, ${ }^{51}$ while the latter reported a $32 \%$ prevalence of PTSD and $39 \%$ prevalence of depression. ${ }^{52}$

\section{Southeast Asia}

Seventeen studies were conducted in Southeast Asia, with six in Vietnam, ${ }^{55-60}$ four in the Philippines, ${ }^{61-64}$ three in Thailand, ${ }^{65-67}$ three in Malaysia ${ }^{306} 69$ and one in Myanmar. ${ }^{29}$ Of those studies reporting follow-up lengths, all but one collected data within a year of the exposure. ${ }^{62}$ PTSD was the most popular outcome, assessed by 16 
Table 3 Summary of evidence for the association between climate change and climate-related disaster exposures and mental disorder outcomes, separated by UN subregion. Note that all studies included in this review fell into 4 of the 19 UN subregions

\begin{tabular}{|c|c|}
\hline UN subregion & Evidence \\
\hline
\end{tabular}

Southeast Asia (17 studies)

In studies with an unexposed group, mental disorders were significantly greater among those exposed vs unexposed to the climate change or climate-related disaster event. ${ }^{55-576165}$

In studies without a baseline/comparator group, the risk factors for mental disorders related to climate change or climate-related disasters were:

- Death/injury (fears or actual): injury, ${ }^{62}{ }^{66}$ thinking you might be seriously injured/die, ${ }^{63}$ being trapped/ having loved ones trapped, ${ }^{63}$ seeing dead bodies/hearing sounds. ${ }^{63}$

Loss/destruction of possessions: material loss, ${ }^{63}$ having a pet die/run away. ${ }^{63}$

- Postdisaster survival: being involved in rescue work, ${ }^{63}$ lack of access to basic needs. ${ }^{62}$

- Greater composite exposure (ie, a sum of relevant individual exposures, for example, death/injury of loved ones, material loss, fear of death and loss of property).

East Asia

(14 studies)
In studies with an unexposed group, mental disorders were significantly greater among those exposed vs unexposed to the climate change or climate-related disaster event. ${ }^{72}$

In studies without a baseline/comparator group, the risk factors for mental disorders related to climate change or climate-related disasters were:

- Death/injury (fears or actual): death/injury of loved ones, ${ }^{7475}$ injury. ${ }^{7475}$

- Loss/destruction of possessions: property damage. ${ }^{74-76}$

- Physical attributes of disaster event: proportion of area affected by event. ${ }^{77}$

- Greater composite exposure (ie, a sum of relevant individual exposures, for example, death/injury of loved ones, material loss, fear of death and loss of property). ${ }^{78-84}$

Latin America and the In studies with an unexposed group, mental disorders were significantly greater among those exposed Caribbean (four studies) vs unexposed to the climate change or climate-related disaster event. ${ }^{89}$

UN, United Nations.

studies with prevalence estimates ranging from $2.5 \%$ to $44.5 \%$. Two studies assessed ASD, reporting prevalence estimates of $2.2 \%$ and $22.5 \%$. Furthermore, two studies measured alcohol-related outcomes; Pollack et a ${ }^{59}$ reported a $2 \%$ prevalence of storm-related alcohol dependence and Sonpaveerawong et at ${ }^{66}$ reported a $17.2 \%$ prevalence of flood-related alcohol misuse.

The two most commonly studied exposures were both typhoons; Xangsane hit Vietnam in 2006 and destroyed nearly 350000 homes $^{70}$ and Haiyan hit the Philippines in 2013 and killed 6300 people. ${ }^{71}$ Amstadter and colleagues ${ }^{55}$ conducted a prospective cohort study of those affected by Xangsane, reporting a post-typhoon prevalence of $2.6 \%$ for PTSD, $5.9 \%$ for major depressive disorder (MDD), $2.2 \%$ for generalised anxiety disorder (GAD) and $9.3 \%$ for panic disorder (PD). Three secondary analyses 565860 were conducted using the original dataset from Amstadter et $a l .{ }^{55}$ Four studies observed those individuals exposed to Haiyan, three of which reported a prevalence of PTSD ranging between $9.4 \%$ and $30 \%$.
Six studies from Southeast Asia included an unexposed group, most of which identified a significant positive exposure-outcome relationship. For example, Lavenda and colleagues ${ }^{61}$ found a significantly greater ASD prevalence among those exposed versus unexposed to Typhoon Haiyan $(\mathrm{p}<0.001)$. Similarly, Amstadter and colleagues $^{55}$ collected subclinical mental disorder data before Typhoon Xangsane (using the Self-Reporting Questionnaire-20; SRQ-20), then re-purposed their study to gather post-typhoon DSM diagnoses to allow for a pre-post comparison. The study showed significant associations between pretyphoon SRQ-20 caseness and posttyphoon PTSD (OR 2.76, 95\% CI 1.10 to 6.93), MDD (OR 2.20, 95\% CI 1.09 to 4.44) and GAD (OR 3.27, 95\% CI 1.17 to 9.15 ), but not PD (OR $1.60,95 \%$ CI 0.89 to 2.86 ). Five additional studies reported associations between climate change or climate-related disaster exposure severity and mental disorder outcomes, with largely mixed results. For example, Sonpaveerawong et $a l^{66}$ found that experiencing flood-related injury was significantly associated with risk 
of suicide (OR 15.39, 95\% CI 2.52 to 94.13) but not of PTSD, depression or alcohol abuse $(\mathrm{p}>0.05)$.

\section{East Asia}

Fourteen studies were conducted in East Asia, all in China. ${ }^{72-85}$ The most common mental disorder outcome was PTSD ( $\mathrm{n}=10$ studies), with prevalence ranging from 9.5\% to $61.9 \%$. Eight studies measured PTSD using the PTSD Checklist-Civilian version, a 17-item self-report instrument that aligns with DSM-IV diagnostic criteria. ${ }^{86}$ Furthermore, 8 of the 14 studies assessed mental disorders after the 1998 flooding of Dongting Lake, which affected approximately 223 million people. ${ }^{87}$ Notably, several studies reported evidence of long-term PTSD due to this event. Dai et $a l^{82}$ and Dai et $a l^{74}$ conducted 15-16year follow-ups of those individuals diagnosed with PTSD by Feng $e t a l^{77} 2$ years post flood, reporting prevalence estimates of 'chronic' PTSD between 15\% and 20\%.

Two of the fourteen studies implemented an unexposed group; both analysed mental disorder hospital admissions using ICD-10 codes. Liu and colleagues ${ }^{72}$ used a case-crossover design to assess the influence of heat waves ( $\geq 3$ days with maximum temperature $\geq 35^{\circ} \mathrm{C}$ ) on mental disorder hospital admissions in the City of Jinan and found a significantly higher number of mean daily admissions during heat wave periods $(\mathrm{p}=0.016)$. Similarly, Zhao $e t a l^{73}$ observed a significant relationship between diurnal temperature range, a known indicator of climate change, ${ }^{88}$ and schizophrenia admissions in the City of Hefei $(p<0.05)$. Eleven studies reported the association between climate change or climate-related disaster exposure severity and mental disorder outcomes, with largely positive results. For example, Dai and colleagues ${ }^{74}$ found that presence of PTSD at 15-16years post flood was significantly associated with experiencing loss of a relative ( $\mathrm{OR}=12.37,95 \%$ CI 2.46 to 62.16$)$ and bodily injury $(\mathrm{OR}=5.01,95 \%$ CI 1.92 to 13.08$)$ at time of disaster. Similarly, Dai $e t a l^{81}$ reported a strong significant association between experiencing $\geq 3$ flood-related stressors (injury, loss of family members, destruction of home, loss of property, etc) and both PTSD (OR 9.48, 95\% CI 2.37 to 27.55) and anxiety (OR 6.19, 95\% CI 2.27 to 19.93 ) at 17-year follow-up.

\section{Latin America and the Caribbean}

Four studies were conducted in Latin America and the Caribbean, with three in Mexico ${ }^{89-91}$ and one in Honduras. ${ }^{92}$ Two of these studies used a prospective cohort design. Kaniasty and Norris ${ }^{91}$ studied 577 floodaffected adults at 6, 12, 18 and 24 months post disaster and reported an initial PTSD prevalence of $24 \%$ with a significant recovery over time $(\mathrm{p}<0.001)$. Kohn ${ }^{92}$ measured PTSD and MDD in hurricane-affected adults at 2 months $(\mathrm{n}=800)$ and again at 2 years $(\mathrm{n}=604)$ post disaster. Prevalence of both disorders remained relatively stable over time (PTSD $10.6 \%$ and $20.5 \%$, MDD $19.5 \%$ and $22.3 \%$ at 2 months vs 2 years).

\section{DISCUSSION}

This scoping review synthesised available evidence on the relationship between climate change and climate-related disaster exposures and mental disorder outcomes in LMICs. The review identified a total of 58 relevant studies spanning 11 countries. Overall, we observed a positive exposure-outcome relationship. Of those studies with an unexposed group, the majority identified a significant positive association between climate change or climaterelated disaster exposures and mental disorder outcomes. Of those studies assessing climate change or climaterelated disaster exposure severity as a risk factor for mental disorders, the majority also identified a significant positive association. These associations were relatively consistent across exposure types, mental disorders and UN subregions. Notably, similar reviews have identified comparable trends. ${ }^{19} 93$ For example, in a global metaanalysis Beaglehole and colleagues ${ }^{93}$ reported a significant increase in postnatural disaster mental disorder outcomes (OR 1.84, 95\% CI 1.43 to 2.38, $\mathrm{p}<0.001, \mathrm{n}=6$ studies).

Despite the overall positive exposure-outcome association identified by this review, it is important to note that many of the included studies did not use a climate change or climate-related disaster unexposed group. For example, just 2/14 studies in East Asia compared mental disorder outcomes between exposed and unexposed individuals. Other reviews in this area have identified a similar gap. ${ }^{194}$ Alternatively, nearly every study presented mental disorder prevalence estimates, which ranged from $0.1 \%$ to $100 \%$. Similarly, among developing countries Rataj et $a l^{19}$ identified post disaster prevalence estimates ranging from $2.6 \%$ to $90 \%$ for PTSD, $5.9 \%$ to $81 \%$ for depression and $2.2 \%$ to $84 \%$ for anxiety. In a global context, Neria et $a \ell^{5}$ reported PTSD prevalence estimates ranging from $3.7 \%$ to $60 \%$ at $1-2$ years post disaster. This wide range in estimates may be attributable to differences in population of interest, sampling technique, follow-up length, outcome measurement and disaster severity, among other factors. Ultimately, with little data on unexposed individuals it is challenging to determine the extent of the association between climate change and climate-related disaster exposures and mental disorder outcomes in LMIC settings. Thus, well-designed studies are needed to further strengthen this evidence base.

The majority of research identified in this review focused on the direct pathways through which climaterelated disaster exposures affect mental health, while just five studies focused on the indirect pathways through which broader climate change exposures affect mental health. Climate-related disasters, such as flooding, storms and heat waves, are relatively easy to quantify. Alternatively, the broader effects of climate change, including displacement and gradual temperature change, are more challenging to identify and measure as they occur over extended periods of time and without set start and end dates. As stated by Berry et $a l,{ }^{96}$ this trend aligns with the broader epidemiological literature where much of 
the focus lies on proximal, rather than distal, causes of disease. Thus, future research should focus on better understanding the mental health impacts of the broader effects of climate change within LMICs, which although less obvious, are no less important.

Relatively few studies explored suicide, substancerelated, bipolar and schizophrenia outcomes, while most explored PTSD, anxiety and depression outcomes. In particular, suicide is the 15th leading cause of death globally. Suicide places a large mortality burden on LMICs, which make up $75 \%$ of global cases. ${ }^{97}$ While the literature has established links between various elements of climate change or climate-related disasters and suicide, ${ }^{98}$ our review suggests that little of this research was conducted in LMICs. One explanation may be the stigma surrounding suicide in these countries. ${ }^{9799}$ Data from the World Mental Health survey showed that of those experiencing suicidality in high-, middle- and low-income countries, $56 \%, 28 \%$ and $17 \%$ sought treatment in the past 12 months, respectively. ${ }^{99}$ Moving forward, efforts should be made to reduce the stigma surrounding suicide and mental health in general within LMICs.

Much of the existing research was concentrated in particular geographic areas, namely southern and eastern Asia. No studies were conducted in South America or Africa. Despite its absence in this body of literature, the IPCC identified Africa as one of the regions most vulnerable to climate change. ${ }^{100}$ Current and future trends indicate serious climate-driven threats to food and water security, crop productivity, infrastructure and economic stability. As identified by Rataj et $a l,{ }^{19}$ poverty likely contributes to a lack of adequate research infrastructure and data reporting among many African countries. Improved data collection and monitoring is essential for understanding the relationship between climate change/ climate-related disasters and mental health and thereby supporting future adaptation efforts. A 2015 review of African climate adaptation initiatives found that just $4 \%$ came from the public health sector. ${ }^{101}$

Of the included studies, $83 \%$ used a cross-sectional design. Other systematic reviews have identified comparable proportions of cross-sectional studies. ${ }^{19}{ }^{20}$ In some cases, the cross-sectional design can be prone to bias. For example, we often cannot determine whether a climaterelated disaster exposure preceded a mental disorder outcome, creating a lack of temporality. Ultimately, we require stronger study designs to better understand the association between climate change and climate-related disaster exposures and mental health outcomes. Others have discussed the utility of longitudinal designs for capturing changes in mental health over time against climate change and climate-related disaster exposures. ${ }^{2796}$ Included in our review, Kaniasty and Norris ${ }^{91}$ measured prevalence of PTSD among residents at 6, 12, 18 and 24 months post flood disaster in Mexico. In the Philippines, Amstadter et $a \tilde{l}^{5}$ assessed the mental health of residents before and after Typhoon Xangsane. While longitudinal studies are generally superior, it is important to consider the context of this research. Many studies took place in a postdisaster setting, presenting various challenges. Particularly in LMICs, infrastructure may not be present to support costly and time-consuming data collection efforts. Factors such as displacement and lack of documentation may limit the ability of researchers to collect repeated measures in these settings. ${ }^{102}$

We observed substantial between-study heterogeneity in terms of outcome measurement. Some studies used formal diagnostic tools based on the DSM or ICD, ${ }^{41} 7692$ while others used validated screening instruments to establish an informal diagnosis. ${ }^{35} 3652$ These differences likely contributed to the observed variation in disorder prevalence estimates. For example, Channaveerachari et $a t^{42}$ reported a PTSD prevalence of $0.7 \%$ among flood-affected individuals in India, assessed by a psychiatrist using ICD-10 criteria. Alternatively, Chung et $a l^{46}$ reported a PTSD prevalence of $100 \%$ after a flood exposure in Pakistan, assessed using the PTSD Diagnostic Scale screening tool. Screening instruments are an important tool for assessing the presence of mental disorders in LMIC settings, where healthcare workers may not be qualified or may not have time to administer complex diagnostic interviews. ${ }^{103}$ In terms of diagnostic tools, differences also exist between the DSM and ICD. In a comparison of the DSM-IV and ICD-10 DCR criteria for PTSD, Peters $e t a^{104}$ reported 12-month prevalence rates of $3 \%$ and $7 \%$, respectively ( $\kappa=0.50$ for level of agreement). Thus, when interpreting and comparing study findings, it is important to consider the outcome assessment tools used.

\section{Strengths and limitations}

This review had several strengths. First, to our knowledge no other scoping or systematic review has addressed our specific research question. Beaglehole et $a \ell^{3}$ conducted a systematic review and meta-analysis of psychiatric disorders and psychological distress after natural disasters; however, they included disasters likely unrelated to climate change and were not LMIC-focused. While Rataj $e t a l^{19}$ and Crabtree ${ }^{20}$ reviewed the mental health impacts of climate-related weather events in developing countries, they did not evaluate the broader, indirect impacts of climate change. Therefore, our review provided a unique understanding of the impacts of climate change and climate-related disasters on mental disorder in LMICs. Second, we conducted the review in accordance with recommendations from the Arksey and O'Malley framework, PRISMA-ScR checklist and JBI Reviewer's Manual, three widely used standards supporting the execution of a high-quality review. As per these standards, two independent reviewers completed the study screening, thereby reducing bias in the evidence selection process. Third, we used rigorous methods to collect evidence for this review. In consultation with a librarian, we searched five electronic databases, recent issues of five relevant journals, and the grey literature. We also performed backward and forward snowballing of all included studies, which 
identified several studies several LMIC-based academic journals including Walailak Journal of Science and Technology (Thailand), CHRISMED Journal of Health and Research (India) and International Journal of Health System and Disaster Management (Iran). In doing so, we minimised the number of studies missed because they were not indexed in the chosen electronic databases.

This review also had limitations. For one, we observed substantial variation in study quality. For example, some studies provided little-to-no information on their sampling techniques, measurement tools and/or statistical analysis. This suggests that our conclusions were not entirely based on high-quality evidence. In addition, we included English-language studies only. As such, 23 nonEnglish studies were excluded at the full-text stage. This decision was made due to project feasibility; however, non-English studies making useful contributions to the research question were therefore excluded. Similarly, we limited our search to exclude sources published before 2007. This was supported by the fact that the IPCC's fourth assessment report was published in 2007, in which the authors first acknowledged the impacts of climate change on human health and well-being. ${ }^{27}$ Nonetheless, we may have excluded relevant studies that were published before 2007. The limitations associated with our search strategy may have prevented us from capturing an entirely comprehensive overview of the literature. Finally, due to the large volume of studies returned by the electronic database search (6971 unique records), we conducted a single-author relevancy screen of all records as the first screening stage. This decision was made due to feasibility purposes, substantially reducing the number of studies left for formal screening by two independent reviewers at the title/abstract stage (2435 records). Although evidence suggests that use of a single reviewer can be suboptimal in some scenarios, ${ }^{105}$ our study only used a single reviewer to screen out the studies that were clearly irrelevant. Therefore, we believe that the proportion of studies missed was lower than if the single reviewer had been using our formal eligibility criteria.

\section{CONCLUSION}

To our knowledge, this was the first scoping review to assess the relationship between climate change and climate-related disaster exposures and mental disorder outcomes within LMICs. Those living in LMICs are particularly vulnerable to the effects of climate change and climate-related disasters and also lack adequate mental health supports. Overall, we observed a positive association between climate change and climate-related disaster exposures and mental disorder outcomes. However, we also observed substantial methodological heterogeneity, likely related to the emergency and under-resourced settings in which many of these studies took place. Moving forward, future research should focus on addressing various gaps in the literature, such as the lack of unexposed groups and geographical non-uniformity.
The findings of this review support the consideration of mental health within LMIC climate change policy. Various policy-level solutions can help to improve mental health within the context of climate change and climate-related disasters, such as improved access and funding for mental health services, increased mental health surveillance and monitoring, adaptation and resilience planning within the mental healthcare system, and specialised mental health training for care providers and first responders. ${ }^{106}$ Overall, this review supports the need to address mental health as a priority in future climate change action.

\section{Twitter Colleen M Davison @colleendavison}

Acknowledgements The authors thank Leena AIShenaiber and Fiona Sharpe for their contributions to the study screening.

Contributors IS and CMD conceptualised and designed the review. IS conducted the searches and both authors performed the study screening. IS drafted the manuscript and CMD reviewed it. Both authors read and approved the final version. CMD is the guarantor for this study.

Funding This study was supported by grants from the Canadian Institutes for Health Research (PJT-162463 and PJT-165971) and Social Sciences and Humanities Research Council (435-2019-1083), PI Frank Elgar. This study was also supported by a Fredrick Banting and Charles Best Canada Graduate Scholarship (Master's Award) from the Canadian Institutes for Health Research.

Map disclaimer The inclusion of any map (including the depiction of any boundaries therein), or of any geographic or locational reference, does not imply the expression of any opinion whatsoever on the part of BMJ concerning the legal status of any country, territory, jurisdiction or area or of its authorities. Any such expression remains solely that of the relevant source and is not endorsed by BMJ. Maps are provided without any warranty of any kind, either express or implied.

Competing interests None declared.

Patient consent for publication Not applicable.

Provenance and peer review Not commissioned; externally peer reviewed.

Data availability statement All data relevant to the study are included in the article or uploaded as supplementary information.

Supplemental material This content has been supplied by the author(s). It has not been vetted by BMJ Publishing Group Limited (BMJ) and may not have been peer-reviewed. Any opinions or recommendations discussed are solely those of the author(s) and are not endorsed by BMJ. BMJ disclaims all liability and responsibility arising from any reliance placed on the content. Where the content includes any translated material, BMJ does not warrant the accuracy and reliability of the translations (including but not limited to local regulations, clinical guidelines, terminology, drug names and drug dosages), and is not responsible for any error and/or omissions arising from translation and adaptation or otherwise.

Open access This is an open access article distributed in accordance with the Creative Commons Attribution Non Commercial (CC BY-NC 4.0) license, which permits others to distribute, remix, adapt, build upon this work non-commercially, and license their derivative works on different terms, provided the original work is properly cited, appropriate credit is given, any changes made indicated, and the use is non-commercial. See: http://creativecommons.org/licenses/by-nc/4.0/.

ORCID iD

Colleen M Davison http://orcid.org/0000-0002-0410-3352

\section{REFERENCES}

1 Intergovernmental Panel on Climate Change $(\mathrm{CH})$. Climate change 2014: synthesis report. contribution of working groups I, II and III to the fifth assessment report of the Intergovernmental panel on climate change. Geneva, $\mathrm{CH}$ : Intergovernmental Panel on Climate Change, 2014. https://www.ipcc.ch/site/assets/uploads/2018/02/ SYR_AR5_FINAL_full.pdf

2 Costello A, Abbas M, Allen A, et al. Managing the health effects of climate change: Lancet and university College London Institute for global health Commission. Lancet 2009;373:1693-733. 
3 Berry HL, Bowen K, Kjellstrom T. Climate change and mental health a causal pathways framework. Int J Public Health 2010;55:123-32.

4 Paranjothy S, Gallacher J, Amlôt R, et al. Psychosocial impact of the summer 2007 floods in England. BMC Public Health 2011;11:145.

5 Liu A, Tan H, Zhou J, et al. An epidemiologic study of posttraumatic stress disorder in flood victims in Hunan China. Can J Psychiatry 2006;51:350-4.

6 Schwartz RM, Gillezeau CN, Liu B, et al. Longitudinal impact of Hurricane sandy exposure on mental health symptoms. Int $J$ Environ Res Public Health 2017;14:957.

7 Kar N, Bastia BK. Post-Traumatic stress disorder, depression and generalised anxiety disorder in adolescents after a natural disaster: a study of comorbidity. Clin Pract Epidemiol Ment Health 2006;2:17.

8 Psarros C, Theleritis C, Economou M, et al. Insomnia and PTSD one month after wildfires: evidence for an independent role of the "fear of imminent death". Int J Psychiatry Clin Pract 2017;21:137-41.

9 Bryant RA, Waters E, Gibbs L, et al. Psychological outcomes following the Victorian black Saturday bushfires. Aust N Z J Psychiatry 2014;48:634-43.

10 Thompson R, Hornigold R, Page L, et al. Associations between high ambient temperatures and heat waves with mental health outcomes: a systematic review. Public Health 2018;161:171-91.

11 Kim Y, Kim H, Gasparrini A, et al. Suicide and ambient temperature: a multi-country multi-city study. Environ Health Perspect 2019;127:117007.

12 Shultz JM, Rechkemmer A, Rai A, et al. Public health and mental health implications of environmentally induced forced migration. Disaster Med Public Health Prep 2019;13:116-22.

13 Cunsolo A, Ellis NR. Ecological grief as a mental health response to climate change-related loss. Nat Clim Chang 2018;8:275-81.

14 Smith KRA, Woodward A, Campbell-Lendrum D. 2014: Human health: Impacts, adaptation, and co-benefits. In: Field CB, Barros VR, Dokken DJ, eds. Impacts, adaptation, and vulnerability Part A: global and sectoral aspects, contribution of working group I/ to the fifth assessment report of the Intergovernmental panel on climate change. Cambridge, UK and New York, NY: Cambridge University Press, 2014: 709-54.

15 Wirtz A. Natural disasters and the insurance industry. In: GuhaSapir D, Santos I, Borde A, eds. The economic impacts of natural disasters. New York, NY: Oxford University Press, 2013: 128-53.

16 Wheeler T, von Braun J. Climate change impacts on global food security. Science 2013;341:508-13.

17 Rathod S, Pinninti N, Irfan M, et al. Mental health service provision in low- and middle-income countries. Health Serv Insights 2017;10:1178632917694350.

18 Saraceno B, van Ommeren M, Batniji R, et al. Barriers to improvement of mental health services in low-income and middleincome countries. Lancet 2007;370:1164-74.

19 Rataj E, Kunzweiler K, Garthus-Niegel S. Extreme weather events in developing countries and related injuries and mental health disorders - a systematic review. BMC Public Health 2016;16:1-12.

20 Crabtree A. Climate change and mental health following flood disasters in developing countries, a review of the epidemiological literature: what do we know, what is being recommended? Australas J Disaster Trauma Stud 2012;2012-1:21-30.

21 Whiteford HA, Ferrari AJ, Degenhardt L, et al. The global burden of mental, neurological and substance use disorders: an analysis from the global burden of disease study 2010. PLoS One 2015;10:e0116820.

22 Grimshaw J. A guide to knowledge synthesis: a knowledge synthesis chapter. Canadian Institutes for health research, 2010. Available: https://cihr-irsc.gc.ca/e/41382.html [Accessed 5 Nov 2020].

23 Tricco AC, Lillie E, Zarin W, et al. PRISMA extension for scoping reviews (PRISMA-ScR): checklist and explanation. Ann Intern Med 2018;169:467.

24 Arksey H, O'Malley L. Scoping studies: towards a methodological framework. Int J Soc Res Methodol 2005;8:19-32.

25 Peters M, Godfrey C, Mclnerney P. Chapter 11: Scoping Reviews (2020 version). In: Aromataris E, Munn Z, eds. Joanna Briggs Institute Reviewer's Manual. JBI, 2020. https://reviewersmanual. joannabriggs.org/

26 World Bank. World bank country and lending groups. world bank data help desk. n.d. Available: https://datahelpdesk.worldbank.org/ knowledgebase/articles/906519-world-bank-country-and-lendinggroups [Accessed 5 Nov 2020].

27 Middleton J, Cunsolo A, Jones-Bitton A, et al. Indigenous mental health in a changing climate: a systematic scoping review of the global literature. Environ Res Lett 2020;15:053001.
28 Godin K, Stapleton J, Kirkpatrick SI, et al. Applying systematic review search methods to the grey literature: a case study examining guidelines for school-based breakfast programs in Canada. Syst Rev 2015;4:138.

$29 \mathrm{Kim} \mathrm{H}$, Han SB, Kim JH, et al. Post-Nargis medical care: experience of a Korean disaster relief team in Myanmar after the cyclone. Eur $J$ Emerg Med 2010;17:37-41.

30 Idris IB, Puteh SEW, Hod R, et al. Mental health disorder among post flood victims in Pahang. ASEAN J Psychiatry 2018;19:1-6.

31 de Bont PAJM, van den Berg DPG, van der Vleugel BM, et al. Predictive validity of the trauma screening questionnaire in detecting post-traumatic stress disorder in patients with psychotic disorders. Br J Psychiatry 2015;206:408-16.

32 Carleton TA. Crop-damaging temperatures increase suicide rates in India. Proc Natl Acad Sci U S A 2017;114:8746-51.

33 Kar N. Suicidality following a natural disaster. Am J Disaster Med 2010:5:361-8

34 Wind TR, Joshi PC, Kleber RJ, et al. The impact of recurrent disasters on mental health: a study on seasonal floods in northern India. Prehosp Disaster Med 2013:28:279-85.

35 Bandla S, Nappinnai NR, Gopalasamy S. Psychiatric morbidity in December 2015 flood-affected population in Tamil Nadu, India. Int $J$ Soc Psychiatry 2019;65:338-44.

36 Viswanathan DJ, Veerakumar AM, Kumarasamy H. Depression, suicidal ideation, and resilience among rural farmers in a DroughtAffected area of Trichy district, Tamil Nadu. J Neurosci Rural Pract 2019;10:238-44.

37 Suar D, Mishra S, Khuntia R. Placing age differences in the context of the Orissa supercyclone: who experiences psychological distress? Asian J Soc Psychol 2007;10:117-22.

38 Dar KA, lqbal N, Prakash A, et al. PTSD and depression in adult survivors of flood fury in Kashmir: the payoffs of social support. Psychiatry Res 2018;261:449-55.

39 Crabtree A. Questioning psychosocial resilience after flooding and the consequences for disaster risk reduction. Soc Indic Res 2013;113:711-28.

40 Ashok V, Premarajan K, Rajkumar R. Mental health status of flood-affected adults in rural Tamil Nadu: a cross-sectional study. CHRISMED J Health Res 2019;6:97-101.

41 Bhat BA, Dar S, Khan MA. Socio-Demographic profile and psychiatric morbidity of flood victims in a mental health cAMP. $J$ Psychiatry 2018;21:1000449.

42 Channaveerachari NK, Raj A, Joshi S, et al. Psychiatric and medical disorders in the after math of the uttarakhand disaster: assessment, approach, and future challenges. Indian J Psychol Med 2015;37:138-43.

43 Deiveegan C, Catherin N, Navya C. Resilience and posttraumatic stress disorder among disaster affected persons attending primary health care, Uttarakhand, India. Int J Health Syst Disaster Manag 2016;4:6-9.

44 Ishikawa M, Yamamoto N, Yamanaka G, et al. Disaster-related psychiatric disorders among survivors of flooding in Ladakh, India. Int J Soc Psychiatry 2013;59:468-73.

45 Telles S, Singh N, Joshi M. Risk of posttraumatic stress disorder and depression in survivors of the floods in Bihar, India. Indian $J$ Med Sci 2009;63:330-4.

46 Chung MC, Jalal S, Khan NU. Posttraumatic stress disorder and psychiatric comorbidity following the 2010 flood in Pakistan: exposure characteristics, cognitive distortions, and emotional suppression. Psychiatry 2014;77:289-304.

47 Akhtar P, Khatoon Z, Vectoria M. Depression among Thari women due to drought at Bodhesar village Nagarparkar Thar. Eur J Med Res 2017;22:P30.

48 Chung MC, Jalal S, Khan NU. Posttraumatic stress symptoms, comorbid psychiatric symptoms and distorted cognitions among flood victims of different ages. J Ment Health 2017;26:204-11.

49 Nasar A, Inayat S, Zulqarnain A. Stress reaction and post-traumatic stress disorder among flood victims of Lahore- Pakistan and role of community (ROC). Int J Psychosoc Rehabil 2016;20:75-84.

50 Qazi S, Alam S, Piracha S. The prevalence of major depression in a rural flood affected area of Pakistan. Pak J Med Health Sci 2014;8:249-52.

51 Rahman A, Akhtar P, Siddiqui MI. Psychological effects among internally displaced persons (IDPS) residing in two districts of Sindh. Med Forum Mon 2013;24:82-4.

52 Solangi M, Zafar S, Moeezudin M, et al. P-979 - Psychiatric morbidity among internally displaced persons (IDPs) of sindh. European Psychiatry 2012;27:1.

53 Jahan S. Assessment of flood related mental illness in Bangladesh, 2015. Available: https://eprints.qut.edu.au/86511/8/Shafkat Jahan Thesis.pdf 
54 Mamun MA, Huq N, Papia ZF, et al. Prevalence of depression among Bangladeshi village women subsequent to a natural disaster: a pilot study. Psychiatry Res 2019;276:124-8.

55 Amstadter AB, Acierno R, Richardson LK, et al. Posttyphoon prevalence of posttraumatic stress disorder, major depressive disorder, panic disorder, and generalized anxiety disorder in a Vietnamese sample. J Trauma Stress 2009;22:180-8.

56 Berenz EC, Trapp SK, Acierno R, et al. Pretyphoon panic attack history moderates the relationship between degree of Typhoon exposure and posttyphoon PTSD and depression in a Vietnamese sample. Depress Anxiety 2013;30:461-8.

57 Trang PM, Rocklöv J, Giang KB, et al. Heatwaves and hospita admissions for mental disorders in northern Vietnam. PLoS One 2016;11:e0155609.

58 Roberson-Nay R, Berenz EC, Acierno R, et al. Characteristics of individuals meeting criteria for new onset panic attacks following exposure to a typhoon. Psychiatry Res 2013;209:574-8.

59 Pollack AA, Weiss B, Trung LT. Mental health, life functioning and risk factors among people exposed to frequent natural disasters and chronic poverty in Vietnam. BJPsych Open 2016;2:221-32.

60 Ritter JD, McCauley JL, Amstadter AB, et al. Mental health correlates of post disaster increases in alcohol and cigarette smoking: a Vietnamese study. Int J Ment Health Addict 2011;9:118-25.

61 Lavenda O, Grossman ES, Ben-Ezra M, et al. Exploring DSM-5 criterion $A$ in acute stress disorder symptoms following natural disaster. Psychiatry Res 2017;256:458-60.

62 Labarda CE, Chan CS. Sleep disturbances, posttraumatic stress, and psychological distress among survivors of the 2013 super Typhoon Haiyan. Psychiatry Res 2018;266:284-90.

63 Chan CS, Tang KNS, Hall BJ, et al. Psychological sequelae of the 2013 super Typhoon Haiyan among survivor-responders. Psychiatry 2016;79:282-96.

64 Sylwanowicz L, Schreiber M, Anderson C, et al. Rapid triage of mental health risk in emergency medical workers: findings from Typhoon Haiyan. Disaster Med Public Health Prep 2018;12:19-22.

65 Yoda T, Yoshioka A, Sakano N. Mental health research for the 2011 flood affected people in Thailand. Trop Med Int Health 2013;18:196.

66 Sonpaveerawong J, Limmun W, Chuwichian N. Prevalence of psychological distress and mental health problems among the survivors in the flash floods and Landslide in southern Thailand. Walailak J Sci \& Tech 2019;16:255-64

67 Assanangkornchai S, Tangboonngam S-nguansri, Sam-angsri $\mathrm{N}$, et al. A Thai community's anniversary reaction to a major catastrophe. Stress and Health 2007;23:43-50.

68 Rasdi I, Zainal Abidin E, SI S. The association between KAP on disasters with depression, GAD and PTSD among flood victims. Indian J Environ Prot 2016;36:888-94.

69 Xiong CZ, Hao HJ, Liong CW. Prevalence of post traumatic stress disorder (PTSD) among flood victims in Malaysia: difference between Kuala Lumpur and Kelantan. Int Med J 2016;23:114-7.

70 Chaudhry P, Ruysschaert G. Climate change \& human development in Viet Nam: A case study. New York, NY: Human Development Report Office, United Nations Development Programme, 2007. http://hdr.undp.org/sites/default/files/chaudhry_peter_and_ ruysschaert greet.pdf

71 Lagmay AMF, Agaton RP, Bahala MAC, et al. Devastating storm surges of Typhoon Haiyan. Int J Disaster Risk Reduct 2015;11:1-12.

72 Liu X, Liu H, Fan H, et al. Influence of heat waves on daily Hospital visits for mental illness in Jinan, China-A case-crossover study. Int $J$ Environ Res Public Health 2019;16:87.

73 Zhao D, Zhang X, Xie M. Is greater temperature change within a day associated with increased emergency admissions for schizophrenia? Sci Total Environ 2016:566-7.

74 Dai W, Wang J, Kaminga AC, et al. Predictors of recovery from post-traumatic stress disorder after the dongting lake flood in China: a 13-14 year follow-up study. BMC Psychiatry 2016;16:382.

75 Dai W, Kaminga AC, Tan H, et al. Comorbidity of post-traumatic stress disorder and anxiety in flood survivors: prevalence and shared risk factors. Medicine 2017;96:e7994

76 Chen G, Shen H, Chen G, et al. The psychological impact of exposure to the 2008 snowstorms on migrant workers in China. Asia Pac J Public Health 2015;27:NP1952-61.

77 Feng S, Tan H, Benjamin A, et al. Social support and posttraumatic stress disorder among flood victims in Hunan, China. Ann Epidemiol 2007;17:827-33.

78 Chen L, Tan H, Cofie R, et al. Prevalence and determinants of chronic post-traumatic stress disorder after floods. Disaster Med Public Health Prep 2015;9:504-8.

79 Zhen R, Quan L, Zhou X. Fear, negative cognition, and depression mediate the relationship between traumatic exposure and sleep problems among flood victims in China. Psychol Trauma 2018;10:602-9.

80 Zhen R, Quan L, Zhou X. How does social support relieve depression among flood victims? the contribution of feelings of safety, self-disclosure, and negative cognition. J Affect Disord 2018;229:186-92

81 Dai $\mathrm{W}$, Kaminga AC, Tan $\mathrm{H}$, et al. Long-Term psychological outcomes of flood survivors of hard-hit areas of the 1998 Dongting lake flood in China: prevalence and risk factors. PLoS One 2017;12:e0171557.

82 Dai W, Chen L, Tan H, et al. Association between social support and recovery from post-traumatic stress disorder after flood: a 13-14 year follow-up study in Hunan, China. BMC Public Health 2016;16:194.

83 Dai W, Kaminga AC, Wu X, et al. Brain-Derived Neurotropic Factor Val66Met Polymorphism and Posttraumatic Stress Disorder among Survivors of the 1998 Dongting Lake Flood in China. Biomed Res Int : 2017;2017:4569698.

$84 \mathrm{Hu} \mathrm{S}$, Tan H, Cofie R, et al. Recovery from post-traumatic stress disorder after a flood in China: a 13-year follow-up and its prediction by degree of collective action. BMC Public Health 2015;15:615.

85 Guo J-C, Tian Z-L, Wang X-D, et al. Post-Traumatic stress disorder after Typhoon disaster and its correlation with platelet 5-HT concentrations. Asian Pac J Trop Med 2016;9:913-5.

86 Ruggiero KJ, Del Ben K, Scotti JR, et al. Psychometric properties of the PTSD Checklist-Civilian version. J Trauma Stress 2003:16:495-502.

87 Zong Y, Chen X, The CX. 1998 flood on the Yangtze, China. Nat Hazards 2000;22:165-84.

88 Braganza K, Karoly DJ, Arblaster JM. Diurnal temperature range as an index of global climate change during the twentieth century Geophys Res Lett 2004;31:n/a.

89 Fernández-Arteaga V, Tovilla-Zárate CA, Fresán A, et al. Association between completed suicide and environmental temperature in a Mexican population, using the knowledge discovery in database approach. Comput Methods Programs Biomed 2016;135:219-24.

90 Jones E, Gupta S, Murphy A, et al. Inequality, socioeconomic status, and social support in post-disaster mental health in Mexico. Hum Organ 2011;70:33-43.

91 Kaniasty K, Norris FH. Longitudinal linkages between perceived social support and posttraumatic stress symptoms: sequential roles of social causation and social selection. J Trauma Stress 2008;21:274-81.

92 Kohn R. Demoralization and the longitudinal course of PTSD following Hurricane Mitch. Eur J Psychiat 2013;27:18-26.

93 Beaglehole B, Mulder RT, Frampton CM, et al. Psychological distress and psychiatric disorder after natural disasters: systematic review and meta-analysis. $\mathrm{Br} J$ Psychiatry 2018;213:716-22.

94 Fernandez A, Black J, Jones M, et al. Flooding and mental health: a systematic mapping review. PLoS One 2015;10:e0119929.

95 Neria Y, Nandi A, Galea S. Post-traumatic stress disorder following disasters: a systematic review. Psychol Med 2008;38:467-80.

96 Berry HL, Waite TD, Dear KBG, et al. The case for systems thinking about climate change and mental health. Nat Clim Chang 2018;8:282-90.

97 World Health Organization $(\mathrm{CH})$. Preventing suicide: a global imperative. Geneva, $\mathrm{CH}$ : World Health Organization, 2014. https:// www.who.int/publications-detail-redirect/preventing-suicide-aglobal-imperative

98 Dumont C, Haase E, Dolber T, et al. Climate change and risk of completed suicide. J Nerv Ment Dis 2020;208:559-65.

99 Bruffaerts R, Demyttenaere K, Hwang I, et al. Treatment of suicidal people around the world. Br J Psychiatry 2011;199:64-70.

100 Niang I, Ruppel OC, Abdrabo MA. Africa. In: Barros VR, Field CB, Dokken DJ, eds. Climate change 2014: impacts, adaptation, and vulnerability. Part B: regional aspects. contribution of working group II to the fifth assessment report of the Intergovernmental panel on climate change. Cambridge, UK and New York, NY: Cambridge University Press, 2014: 1199-265. https://www.ipcc.ch/report/ar5/ wg2/africa/

101 Ford JD, Berrang-Ford L, Bunce A, et al. The status of climate change adaptation in Africa and Asia. Reg Environ Change 2015:15:801-14.

102 Mukherji A, Ganapati NE, Rahill G. Expecting the unexpected: field research in post-disaster settings. Nat Hazards 2014;73:805-28.

103 Ali G-C, Ryan G, De Silva MJ. Validated screening tools for common mental disorders in low and middle income countries: a systematic review. PLoS One 2016;11:e0156939. 
104 Peters L, Slade T, Andrews G. A comparison of ICD10 and DSMIV criteria for posttraumatic stress disorder. J Trauma Stress 1999;12:335-43.

105 Waffenschmidt S, Knelangen M, Sieben W, et al. Single screening versus conventional double screening for study selection in systematic reviews: a methodological systematic review. BMC Med Res Methodol 2019;19:1-9.

106 Hayes K, Blashki G, Wiseman J, et al. Climate change and mental health: risks, impacts and priority actions. Int J Ment Health Syst 2018;12:28. 